\title{
IMPRENSA E INEFETIVIDADE DO DIREITO À MORADIA: O MTST NA FOLHA DE S. PAULO
}

\author{
THE PRESS AND INEFFECTIVENESS OF THE RIGHT TO HOUSING: MTST \\ IN FOLHA DE S. PAULO
}

\section{LA PRENSA Y LA INEFICACIA DEL DERECHO A LA VIVIENDA: EL MTST EN FOLHA DE S. PAULO}

Beatriz Trezzi Vieira Jornalista, docente e doutora em Direitos Humanos Universidade de São Paulo beatrizvieira@uol.com.br

\begin{abstract}
Resumo
Este artigo busca compreender como o Movimento dos Trabalhadores Sem Teto (MTST), seus integrantes e sua luta pela conquista à moradia no Brasil foram representados pela Folha de S. Paulo, a partir da colaboração do líder do movimento para o site do jornal, entre 2014 e 2017. Por meio de análise quantitativa e qualitativa da cobertura feita pelo veículo sobre os sem-teto, utilizando-se como base metodológica a Análise Crítica do Discurso, com aportes de elementos e categorizações da produção jornalística, bem como de verificação das formas de representação discursiva e imagética empregadas na amostra, objetivou-se verificar se, nas narrativas textuais e imagens veiculadas, o veículo buscou contribuir para a compreensão da luta pelo direito à moradia no país. A análise permitiu concluir, entretanto, que a naturalização da inefetividade desse direito social é corroborada discursivamente nas narrativas em questão.
\end{abstract}

Palavras-chave: Direito à Moradia. Jornalismo. MTST.

\begin{abstract}
This article seeks to understand how the Homeless Workers Movement (MTST), its members and their struggle for housing in Brazil were represented by Folha de S. Paulo in the period of the movement's leader's collaboration for the vehicle's website, between 2014 and 2017. Through quantitative and qualitative analysis of the newspaper's coverage of the homeless, having the Critical Discourse Analysis as a methodological basis along with contributions of elements and categorizations of journalism, as well as observation of the discursive and imagery representations employed in the sample, the aim was to verify whether the vehicle sought to contribute to the understanding of the struggle for housing in the textual narratives and images conveyed. However, the analysis allowed us to conclude that the naturalization of the ineffectiveness of this social right was discursively corroborated in the reports.
\end{abstract}

Keywords: Right to Housing. Journalism. MTST. 


\section{Resumen}

Este artículo busca comprender cómo el Movimiento de Trabajadores Sin Hogar (MTST), sus miembros y su lucha por la vivienda en Brasil fueron representados por Folha de S. Paulo, a partir de la colaboración del líder del movimiento para el sitio web del vehículo, entre 2014 y 2017. A través del análisis cuantitativo y cualitativo de la cobertura de las personas sin hogar, utilizando como base metodológica el Análisis Crítico del Discurso, con aportes de elementos y categorizaciones de la producción periodística, así como la verificación de las formas de representación e imaginería empleadas en la muestra, el objetivo fue verificar si en las narrativas textuales e imágenes transmitidas, el vehículo buscaba contribuir a la comprensión de la lucha por el derecho a la vivenda. El análisis permitió concluir, sin embargo, que la naturalización de la ineficacia de este derecho se corrobora discursivamente en las narrativas.

Palabras clave: Derecho a la Vivienda. Periodismo. MTST.

\section{INTRODUÇÃO}

O direito à moradia foi incluído na Constituição de 1988 pela Emenda Constitucional $\mathrm{n}^{\circ} 26$, de 2000 , passando a fazer parte dos direitos sociais expressos no artigo $6^{\circ}$ da Carta - Capítulo II; Dos Direitos Sociais; Título II; Dos Direitos e Garantias Fundamentais -, ao lado de educação, saúde, trabalho, lazer, segurança, previdência social, proteção à maternidade e à infância e assistência aos desamparados (BRASIL, 1988) ${ }^{1}$.

O reconhecimento constitucional, entretanto, não afastou de todo os obstáculos e dificuldades de concretização desse e dos demais direitos sociais no país, tendo em vista que esses dependem de recursos orçamentários e atuação efetiva do Estado para a garantia de seu cumprimento. $\mathrm{O}$ direito à moradia, em particular, é um dos que sofrem com a morosidade em ser concretizado, uma vez que não está prevista na Constituição a vinculação orçamentária para sua implementação por parte dos entes federativos, como é o caso da saúde (artigo 198, parágrafo $2^{\circ}$, I) e da educação (artigo 212). Embora trate-se de compromisso e dever do Estado, reconhecido após uma série de trâmites legislativos e envolvendo reivindicações legítimas da sociedade civil, é recorrente a invocação da limitação material para justificar a realização de forma apenas gradual desses direitos fundamentais, levando na prática a sua inefetividade.

Ainda que, no país, tenha havido avanços em termos de inovações legislativas e políticas públicas pós-Emenda Constitucional $\mathrm{n}^{\circ} 26$, em especial nos anos 2000, com a

\footnotetext{
${ }^{1}$ A alimentação e o transporte, foram incluídos no mesmo artigo pela Emenda Constitucional no 90, de 2015.
} 
promulgação do Estatuto da Cidade (Lei n 10.257, de 2001) e o Programa Minha Casa, Minha Vida (Lei ${ }^{\circ}$ 11.977, de 2009), o fato é que ainda estamos muito longe de superar o problema do déficit habitacional ${ }^{3}$ e da dramática desigualdade de condições de vida nas cidades brasileiras (ROLNIK, 2015).

Os grandes propulsores da luta pela moradia e responsáveis diretos por essas conquistas foram os movimentos populares urbanos organizados, que desde a década de 1980 vêm demandando políticas para a efetivação dos direitos sociais. Dentre eles, está o Movimento dos Trabalhadores Sem-Teto (MTST), que iniciou sua atuação em 1997 com as primeiras ações na região de Campinas, no estado de São Paulo, tendo surgido como uma espécie de braço urbano do Movimento dos Trabalhadores Sem Terra, o MST. Anos mais tarde, O MTST ganharia projeção nacional tornando-se um dos protagonistas das manifestações populares que tomaram o país em junho de 2013 e por ocasião da Copa do Mundo realizada no Brasil em 2014.

Dos sem-terra, foram herdadas concepções, princípios e a própria forma de atuação coletiva organizada. Entretanto, ao longo do tempo, o MTST foi adquirindo características e estratégias próprias, tanto na forma de atuar quanto no posicionamento político e, já em 2001, adquiriu autonomia em relação ao MST (BOULOS, 2014; SIMÕES, CAMPOS, RAFAEL, 2017).

O MTST vem empreendendo uma luta que vai além das demandas pelo direito à moradia, ao ampliar o rol de reivindicações no sentido de enfrentar as carências e dificuldades que afetam as massas urbanas excluídas, alijadas da infraestrutura básica de serviços a que está relegada a maioria dos moradores das periferias das grandes cidades brasileiras.

Nesse esforço, além da ação direta por meio de ocupações, marchas e manifestações, o movimento, em sua trajetória de mais de duas décadas, já realizou acampamentos em áreas públicas pelo país, entre as quais praças e regiões centrais das

\footnotetext{
${ }^{2}$ O estatuto regulamenta o capítulo da política urbana da Constituição. Entre suas diretrizes, prevê a realização plena do instituto da função social da propriedade urbana, a regularização fundiária e a urbanização de áreas ocupadas por populações de baixa renda.

${ }^{3}$ Os dados mais atualizados da Fundação João Pinheiro, estudo oficial utilizado pelo governo federal como referência sobre a questão da moradia, mostram que, em 2015, o déficit habitacional brasileiro correspondia a 6,3 milhões de domicílios (FUNDAÇÃO JOÃO PINHEIRO, 2018). O déficit é medido pelo número de famílias sem moradia, pelas que moram em condições precárias de habitação e sem serviços básicos, como serviços de água, energia, saneamento ou coleta de lixo, pelos que vivem em situação de coabitação familiar e pelas famílias com renda domiciliar de até três salários mínimos que comprometam $30 \%$ ou mais da sua renda para aluguel.
} 
cidades e em frente a prefeituras, secretarias e câmaras municipais, a fim de exercer pressão sobre as autoridades para o atendimento a suas reivindicações. Outras formas de atuar foram fazendo greve de fome em locais de grande visibilidade, acorrentamento de militantes e a interrupção do transporte em rodovias ou grandes avenidas, ações conhecidas como "travamentos" ou "trancamentos".

À parte as lutas pelo direito à moradia, O MTST incorporou também outras bandeiras, como a reforma urbana e o poder popular, que se traduzem na mobilização pela redução das desigualdades na cidade e na articulação com os mais diversos grupos que atuam nas periferias, para engajamento e fortalecimento das lutas conjuntas (GOULART, 2011).

\section{DESENVOLVIMENTO}

\subsection{O MTST na Folha de S. Paulo}

Em junho de 2014, Guilherme Boulos, coordenador nacional do Movimento dos Trabalhadores Sem Teto (MTST), iniciou colaboração semanal para o jornal Folha de S. Paulo na internet. $O$ fato chamava a atenção em virtude das posições políticas do representante dos sem-teto e de seu grupo: à esquerda do espectro político e adotando ações diretas de ocupação, de maneira geral recebidas com rejeição ou desconfiança por parte da grande imprensa e do público.

Para o representante dos sem-teto, aceitar a coluna representava um "esforço de dialogar com um público mais amplo do que aquele que está próximo dos movimentos sociais", segundo ele mesmo afirmaria posteriormente (BOULOS, 2017). Para a Folha, em tese, trazia a possibilidade de ampliar a representatividade de seu time de colunistas, em consonância com o princípio editorial da pluralidade que o jornal defende e que está expresso em seu Manual de Redação (FOLHA DE S. PAULO, 2011, 2018).

A colaboração de Boulos suscitou o interesse em compreender de que forma se daria o "diálogo" entre as ideias do movimento, por meio de seu representante, e a cobertura do jornal sobre o MTST, suas reivindicações e ações, isto é, se esta cobertura ganharia mais espaço editorial e passaria a evidenciar uma maior receptividade do veículo a tais demandas. 
A partir daí, surgiram indagações como: poderia a voz do MTST, ao assumir uma coluna semanal no veículo líder em circulação nacional ${ }^{4}$, abrir um novo canal de interlocução com o público leitor e internauta - uma parcela da população com poder aquisitivo suficiente para consumir jornais e ter acesso a portais de conteúdo, via de regra não afetada pelo problema da falta de moradia ${ }^{5}$, tendo essa ação o efeito fazer avançar a aceitação e o reconhecimento da legitimidade do que reivindica o movimento?

Em relação à Folha, as perguntas iniciais foram: ao abrir espaço para as ideias e demandas do movimento, em geral ignoradas e até mesmo rejeitadas por grande parte da população, o jornal demonstrava ir ao encontro de uma possível abertura por parte do público para essas questões e, concretamente, essa decisão teria o potencial de trazer maior visibilidade às lutas por moradia, contribuindo para as conquistas que os sem-teto almejam?

Partindo de respostas afirmativas a essas questões, chegava-se à hipótese de que, ao apresentar suas demandas e reivindicações na Folha de S. Paulo por meio de seu coordenador, o MTST, na luta pela efetividade do direito à moradia, ganharia uma nova plataforma de visibilidade, ao ter possivelmente ampliada a cobertura de suas ações pelo jornal e expandida a compreensão, em meio a parcelas de leitores, sobre as razões e a premência do que reivindica.

Dessa forma, objetivou-se verificar como se deu a cobertura do jornal sobre as ações do movimento a partir da presença de Boulos como articulista e se essa cobertura como o jornal apresenta o grupo e suas causas - modificou-se em virtude de ter aberto espaço ao MTST e aos sem-teto, na coluna. Para essa tarefa, tomou-se por base teórico-metodológica o paradigma da Análise Crítica do Discurso (ACD), na abordagem concebida pelo linguista britânico Norman Fairclough (2001), utilizando-se nessa análise elementos de referência e categorizações da produção jornalística, bem como procedendo-se à verificação das formas de representação discursiva e imagética empregadas na cobertura em questão.

Partiu-se de um levantamento na base de dados do jornal na internet das palavraschave "direito à moradia", "Movimento dos Trabalhadores Sem Teto" e "Guilherme Boulos",

\footnotetext{
4 À época, a Folha de S. Paulo era o jornal com maior média diária de circulação impressa e de assinaturas digitais do país, alcançando 371.050 leitores em dezembro de 2014, segundo o IVC Brasil (Instituto Verificador de Comunicação). Disponível em https://ivcbrasil.org.br/\#/auditorias. Acesso em: 15 fev. 2020.

${ }^{5}$ Segundo informava a Folha de S. Paulo em seu site à época, seu público consumidor estava distribuído em termos de poder aquisitivo da seguinte forma: classe A, 28\%; B, 25\%; C, 40\%; e E, 7\% (FOLHA DE S. PAULO, 2018).
} 
para chegar aos registros encontrados em um período anterior, simultâneo e posterior àquele em que o líder do MTST colaborou para a Folha Digital (26 de junho de 2014 a 9 de março de 2017), delimitando-se essa busca entre $1^{\circ}$ de janeiro do primeiro ano de colaboração e 31 de dezembro do ano de término.

Do resultado retornado, em primeiro lugar, foram identificados os registros dos artigos de Boulos e, separadamente, das diversas categorias encontradas que englobavam textos jornalísticos informativos (notas, notícias, entrevistas pingue-pongue e reportagens) e opinativos (editoriais, colunas de articulistas, colunas do ombudsman do jornal e mensagens de manifestação dos leitores), veiculados pela edição impressa e online do jornal no período. ${ }^{6}$ Dessa forma, tornou-se possível verificar a trajetória do espaço que o jornal concedeu aos temas buscados, ao longo do período pesquisado.

Especificamente para a análise qualitativa, foi selecionada amostra de reportagens sobre ações e fatos envolvendo os temas relativos às palavras-chave no período. $\mathrm{O}$ formato

\footnotetext{
${ }^{6}$ Nesse levantamento, seguiu-se a classificação atualizada por Marques de Melo e Assis (2010) sobre os gêneros jornalísticos brasileiros, nos quais estão categorizados os diversos formatos, com o contributo, ainda, do Manual de Redação da Folha (FOLHA DE S. PAULO, 2011). Seguem, apresentados de forma resumida e após observação do material coletado na pesquisa:
}

\section{Gênero informativo}

Nota - Notícia mais curta, de um ou dois parágrafos, em geral sem entrevistas.

Notícia - Relato de um fato, com mais de três parágrafos e, no máximo, cinco ou seis com, pelo menos, uma entrevista.

Reportagem - Relato mais aprofundado, com maior número de parágrafos e diversas entrevistas.

Entrevista pingue-pongue - Na definição do Manual de Redação da Folha que vigia à época esse tipo de entrevista era publicada na forma de perguntas e respostas, com texto introdutório contendo a informação de mais impacto, breve perfil do entrevistado e outras informações, como local, data e duração da entrevista e resumo do tema abordado. FOLHA DE S. PAULO, Manual da Redação: São Paulo: Publifolha, 2001, p. 67.

\section{Gênero opinativo}

Editorial - Artigo que aparece, na Folha de S. Paulo, à página 2, na coluna à esquerda, com a opinião do jornal sobre determinado fato. Diferentemente dos artigos, não é assinado.

Artigo - Publicado periódica ou esporadicamente, com a opinião de algum convidado ou articulista contratado pelo jornal ou da própria equipe de jornalistas.

Coluna - Espaço fixo de um jornalista ou especialista convidado pelo jornal, que traz a análise sobre os fatos cotidianos. Na Folha, inclui-se a coluna do Ombudsman, jornalista encarregado receber críticas, sugestões e reclamações de leitores e de realizar análises críticas sobre as edições.

Opinião do leitor - Espaço de reprodução de manifestações de leitores sobre as notícias ou opiniões que aparecem nos jornais. 
reportagem foi escolhido, em virtude de apresentar textos mais extensos que as demais categorias, permitindo, a princípio, oferecer uma visão mais aprofundada dos diversos vieses da cobertura sobre os sem-teto. ${ }^{7}$

\subsection{Análise quantitativa}

A contabilização dos registros separados em formatos jornalísticos, incluindo a coluna de Guilherme Boulos, mostra um número maior de "reportagens" em relação aos demais formatos ${ }^{8}$. Tal resultado poderia indicar, a princípio, um possível aprofundamento da cobertura feita pelo jornal, uma vez que a reportagem é caracterizada por apresentar textos mais extensos que os da nota e da notícia, o que, por conseguinte, possibilitaria entrevistar um número maior de fontes e dedicar mais espaço ao aprofundamento de informações e dados de contextualização sobre os temas abordados (Gráfico 1).

\footnotetext{
${ }^{7}$ No levantamento para a pesquisa da qual se extraiu este artigo, foram selecionados também para análise qualitativa os 52 textos do primeiro ano de colaboração do coordenador dos sem-teto para a Folha de S. Paulo. Os artigos foram analisados do ponto de vista discursivo, com o intuito de identificar as estruturas argumentativas utilizadas pelo articulista para estabelecer "diálogo" com os leitores/internautas.

${ }^{8}$ Os resultados dos registros incluíram: a coluna de Guilherme Boulos - 129 artigos (9 registros de avisos sobre a ausência de colaboração do colunista nessas ocasiões e 1 errata não foram considerados); e formatos jornalísticos - 8 notas; 99 notícias; 147 reportagens; 2 entrevistas pingue-pongue; 11 artigos; 11 colunas do staff da Folha e de convidados e 2 colunas do Ombudsman; e 6 manifestações de leitores sobre os temas pesquisados. Foi considerada a coluna de Boulos a fim de verificar o espaço total que o jornal concedeu a esses temas.
} 
Gráfico 1 - Resultado da pesquisa de formatos jornalísticos por palavras-chave mais a coluna de Guilherme Boulos no período de janeiro de 2014 a dezembro de 2017.

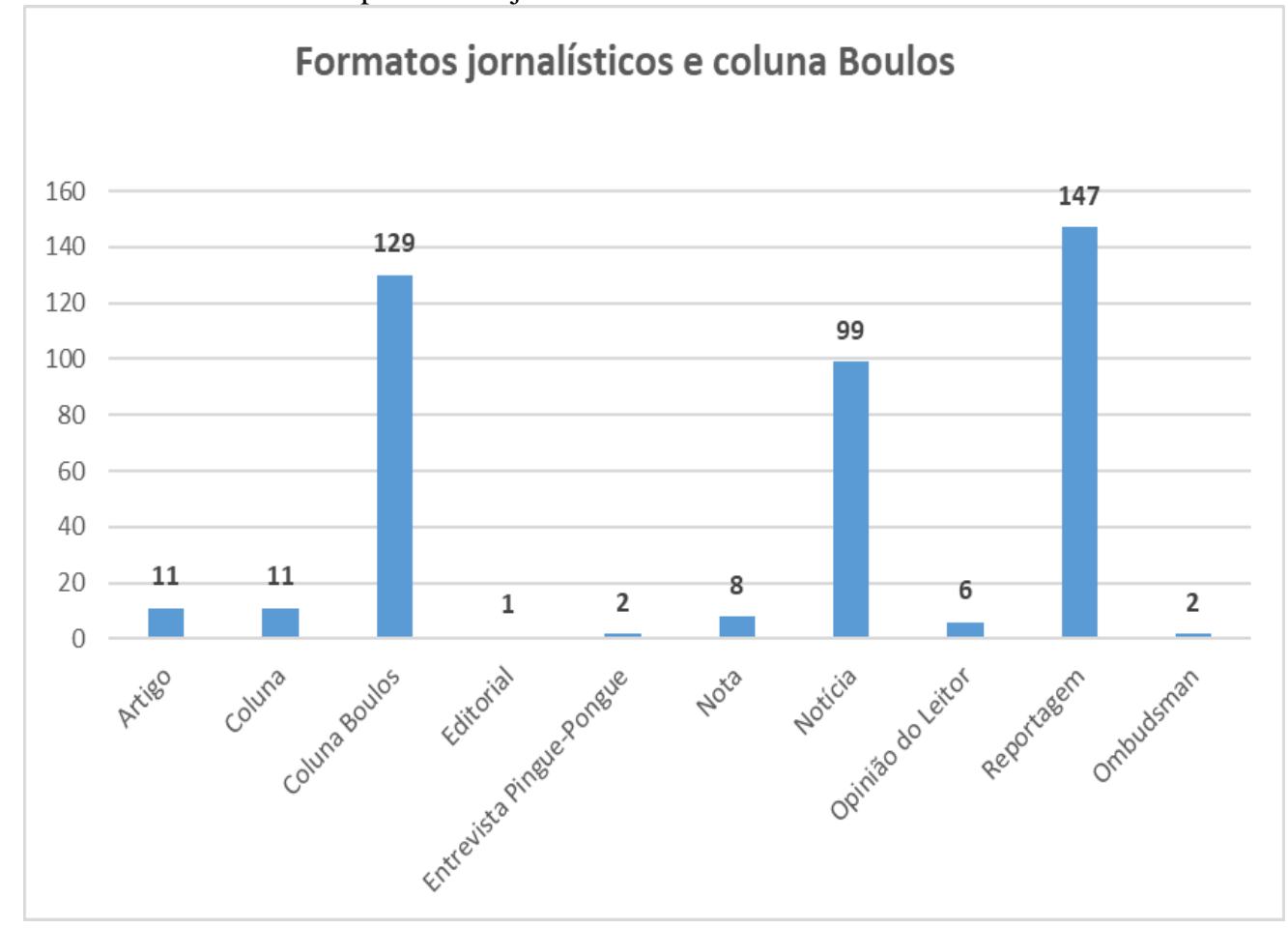

Entretanto, quando considerados os registros ao longo do período abrangido com o intuito de verificar o espaço concedido aos temas pesquisados a partir do início da coluna, dessa forma, sem sua contabilização -, constata-se que a maior ocorrência se deu no primeiro semestre de 2014 (Gráfico 2). Esse foi o momento em que o MTST realizou uma série de ocupações e manifestações em São Paulo e em outros estados antes da realização da Copa do Mundo de futebol, como protesto contra os altos investimentos do país para receber o evento. 
Gráfico 2 - Resultado da pesquisa de formatos jornalísticos por palavras-chave sem a coluna de Guilherme Boulos no período de janeiro de 2014 a dezembro de 2017.

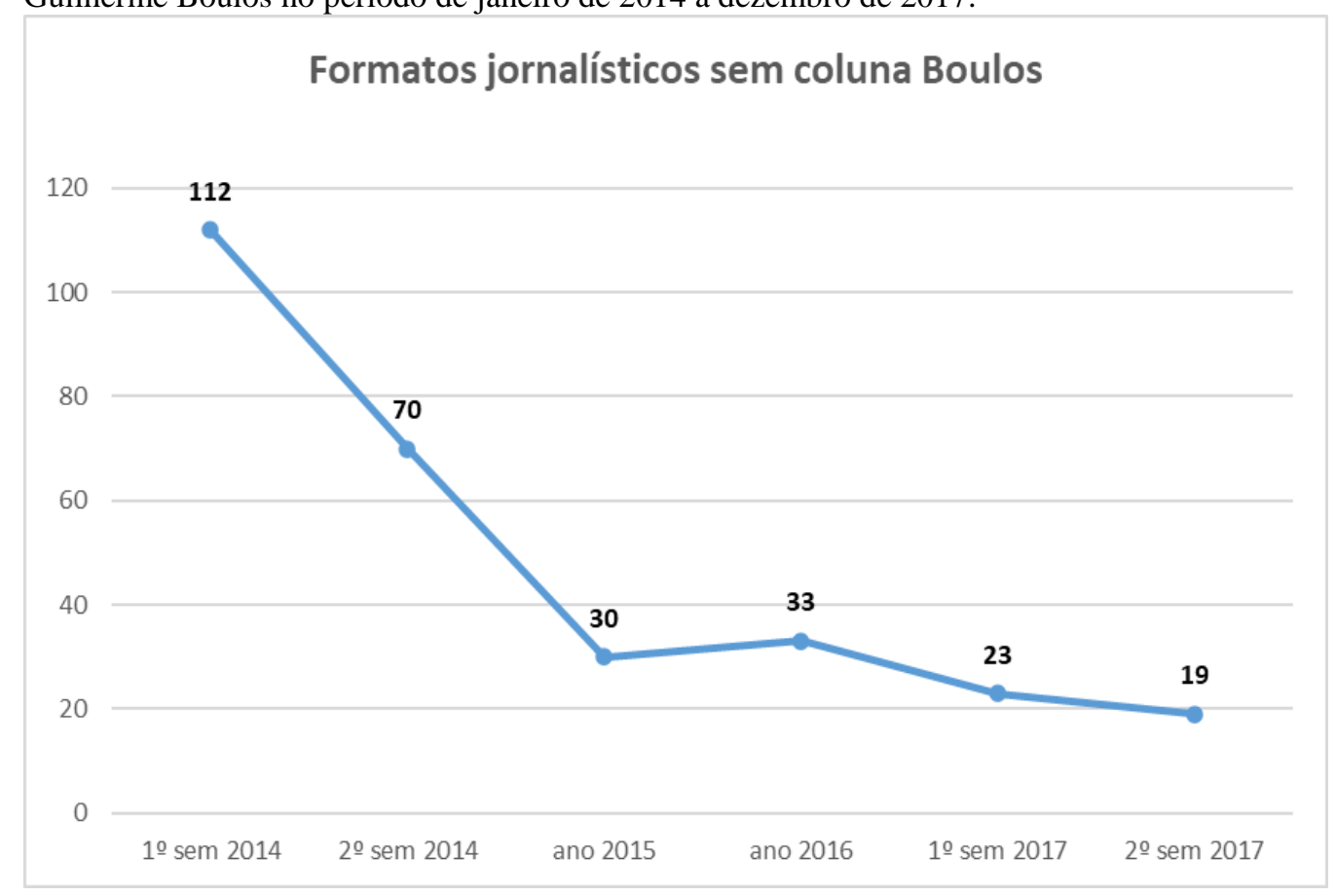

Uma inferência possível a partir dos resultados é que esses fatos tenham motivado a cobertura jornalística em virtude de sua visibilidade e, consequentemente, pelo interesse que poderiam suscitar no público leitor. Tal evidência explicaria, da mesma forma, o convite da Folha ao líder do MTST para integrar seu time de colaboradores.

Entretanto, os registros vão-se reduzindo acentuadamente a partir do segundo semestre de 2014. Essa tendência poderia ser explicada pelo fato de o MTST ter diminuído significativamente a quantidade de ocupações e manifestações, à medida que tomava corpo o movimento pelo impeachment da presidente Dilma Rousseff ${ }^{9}$. Dilma contava com o apoio do MTST, embora os sem-teto e seu líder verbalizassem críticas às políticas econômicas de cunho liberal adotadas pelo governo. O menor número de manifestações e ações do MTST, por sua vez, explicaria uma redução da cobertura por parte do jornal.

O movimento, porém, voltou a realizar atos de impacto em 2016, tanto durante o processo de impeachment como depois de seu desfecho, e também após a posse de Michel Temer como presidente, em protesto contra as medidas de restrição de gastos e projetos de lei

\footnotetext{
${ }^{9} \mathrm{O}$ primeiro ano do segundo mandato da presidente (2015) foi marcado por uma série de manifestações públicas contrárias ao governo, coincidindo com o marco de um ano da Operação Lava Jato e ganhando impulso com a crescente oposição do então presidente da Câmara dos Deputados, Eduardo Cunha (PMDB-RJ), ao Executivo.
} 
de redução de direitos trabalhistas adotadas pelo governo, que contava com o apoio da grande mídia. A ação de maior repercussão foi a ocupação que ocorreu em frente ao escritório da Presidência da República em São Paulo, o que levou o MTST a obter concessões do governo. ${ }^{10} \mathrm{O}$ fim da colaboração de Boulos, anunciado por ele próprio na coluna do dia seguinte ao fim da ocupação, estaria relacionado a esse fato, segundo ele.

Em seu último texto, Boulos informa sobre a decisão do jornal:

$\mathrm{O}$ argumento dado foi de uma renovação "natural", uma rotatividade de colunistas. Pode ser. Porém, até pelo momento em que ocorre, me parece impossível não relacionar o gesto ao acampamento do MTST (Movimento dos Trabalhadores Sem Teto) na Paulista, com todas as reações de hostilidade que gerou em empresários e associações sediadas naquela avenida (BOULOS, 2017).

Um mês após deixar a Folha, o líder dos sem-teto passou a assinar uma coluna quinzenal nas edições digital e impressa da revista Carta Capital, para a qual colabora até o momento de finalização deste artigo (meados de 2021).

No ano seguinte (março de 2018), Boulos filiou-se ao Partido Socialismo e Liberdade (PSOL) lançando-se pré-candidato à Presidência da República, ao lado da líder indígena Sônia Guajajara como vice. A campanha posterior sustentou-se em uma frente de esquerda apoiada, além do PSOL, pelo Partido Comunista Brasileiro (PCB), MTST, Mídia Ninja e outros ativistas pela democratização da comunicação, representantes dos povos indígenas, movimentos estudantis, feministas, movimento negro, LGBTQIA+, artistas, professores e líderes religiosos, entre outros.

A candidatura levantou bandeiras como a luta pela redução das desigualdades sociais e a necessidade do aperfeiçoamento democrático por meio da participação popular, em um momento de retrocessos na conquista de direitos com as reformas liberais promovidas pelo governo Temer e de avanço do conservadorismo no país, com o crescente apoio angariado pelo candidato de direita, Jair Bolsonaro (PSL-RJ), à presidência. Tendo obtido

\footnotetext{
${ }^{10}$ No dia 16 de fevereiro de 2017, o MTST ocupou a calçada na frente do escritório da Presidência da República na avenida Paulista, em protesto contra a paralisação nas contratações da Faixa 1 do Programa Minha Casa, Minha Vida, voltado para famílias de menor renda (até R $\$ 1,8$ mil) e da modalidade Entidades do programa (realizada em cogestão com movimentos por moradia, entre os quais o MTST), promovida pelo governo Temer. O acampamento, batizado de "Ocupa Paulista", durou 22 dias, até que, em 8 de março, o ministro das Cidades, Bruno Araújo, recebeu representantes do movimento e acabou por anunciar a contratação de 170 mil novas unidades habitacionais na primeira faixa, em contrapartida à desocupação na Paulista.
} 
617.122 votos $(0,58 \%)$, Boulos ficou em décimo lugar no primeiro turno das eleições presidenciais de 2018.

Dois anos depois, o líder do MTST decidiu lançar-se candidato a prefeito de São Paulo, também pelo PSOL, ganhando impulso com o respaldo de apoiadores do espectro da centro-esquerda. A adesão de eleitores mais jovens, numa campanha forte nas redes sociais e com pouco tempo de TV, levou a candidatura ao segundo turno do pleito contra Bruno Covas (PSDB-SP), que buscava a reeleição. Boulos perdeu a disputa municipal, obtendo 40,6\% dos votos válidos.

Com o resultado, o candidato ampliou sua projeção num momento em que o campo político da esquerda intensificava a discussão sobre os possíveis cenários para a sucessão presidencial de 2022. Em janeiro de 2021, Boulos voltou a integrar o grupo de colunistas da Folha, escrevendo desta vez também para o jornal impresso (coluna vertical da página A2 às terças-feiras), além da plataforma digital. Um mês depois, o líder do MTST foi eleito pela revista americana Time, em sua lista anual Time 100 Next, uma das 100 lideranças emergentes com potencial de notabilizar-se no futuro. ${ }^{11}$

\subsection{Análise qualitativa}

Para a análise qualitativa, foi selecionada uma amostra de oito reportagens a partir da pesquisa por palavras-chave realizada na base de dados da Folha: (1) TUROLLO JR., 2014; (2) ROSATI; SANT'ANNA, 2014; (3) FÁBIO, 2014; (4) CAMARGO, 2015; (5) ALVES, 2015; (6) CAMARGO, 2016; (7) TUROLLO JR.; RODRIGUES, 2017; e (8) ZYLBERKAN, 2017. Essas foram escolhidas sob o ponto de vista da cobertura da Folha sobre ações representativas e diversificadas do MTST (ocupações, manifestações de protesto e atos de resistência a reintegrações de posse) ao longo do período de janeiro de 2014 a dezembro de 2017 , totalizando oito semestres.

A proposta foi a de verificar em que medida o conteúdo textual da amostra conteria ou não subsídios para a construção de um debate público sobre as reivindicações apresentadas por atores sociais como o MTST ou se, ao contrário, as reportagens contribuiriam para reforçar a criminalização, estigmatização ou invisibilização desse grupo na

\footnotetext{
11 MAtToso, Camila. Folha de S. Paulo. Painel. 17 fev. 2021. Revista Time escolhe Boulos um dos 100 líderes emergentes globais. Disponível em: https://www1.folha.uol.com.br/colunas/painel/2021/02/revista-timeescolhe-boulos-um-dos-100-lideres-emergentes-globais.shtml. Acesso em 10 jun. 2021.
} 
esfera pública brasileira. As reportagens foram analisadas utilizando-se elementos e categorias da produção jornalística como: escolhas lexicais presentes em títulos, linhas-finas e textos; angulação ou enfoque adotado pelo jornal $^{12}$; fontes entrevistadas; contextualização das temáticas apresentadas e imagens mostradas nas matérias.

Nessa análise, procurou-se focalizar também os modos de representação ${ }^{13}$ presentes nos discursos, com o intuito de depreender seu potencial para a construção de sentidos sobre os sem-teto e suas ações, por exemplo, por meio da observação de expressões escolhidas pelo jornal nos textos ao relatar notícias sobre o MTST, como a utilização dos termos "invasão", em lugar de "ocupação" (termo empregado pelos sem-teto) para qualificar as ações do movimento.

Registra-se, nesse sentido, que a ombudsman da Folha Vera Guimarães Martins (2014) comentou, em sua coluna do domingo posterior à estreia de Boulos como colunista no jornal, a opção editorial da Folha entre a utilização dos termos "invadir" e "ocupar". Segundo ela, a palavra invadir seguia a nomenclatura determinada pelo jornal, uma vez que a Folha “condena a invasão de propriedade privada", dessa forma posicionando-se de forma diferente do movimento, que utiliza o termo ocupar.

Em particular nesse quesito observou-se que a expressão "invasão", o verbo invadir ou a categorização "invasores" foram utilizados de forma predominante na amostra selecionada. Somente em uma reportagem, a de número 5 (Imagem 1), é empregada a expressão ocupação e suas variantes ocupantes e ocupar, tanto no título como no corpo do texto.

\footnotetext{
${ }^{12}$ De acordo com Cremilda Medina (1978, pp. 73-78), no jornalismo informativo ou interpretativo, a angulação é um componente estrutural presente no processo de produção da mensagem jornalística que se traduz no enfoque e nos elementos de codificação presentes tanto nas coberturas realizadas como na divulgação de notícias, em função do posicionamento ideológico e mercadológico das empresas.
}

${ }^{13}$ Entendidos como efeitos de sentido que os textos potencialmente produzem de acordo com o modo em que estão organizados e conforme a relação do discurso com outros elementos da prática social. (FAIRCLOUGH, 2001, pp. 155-157) 


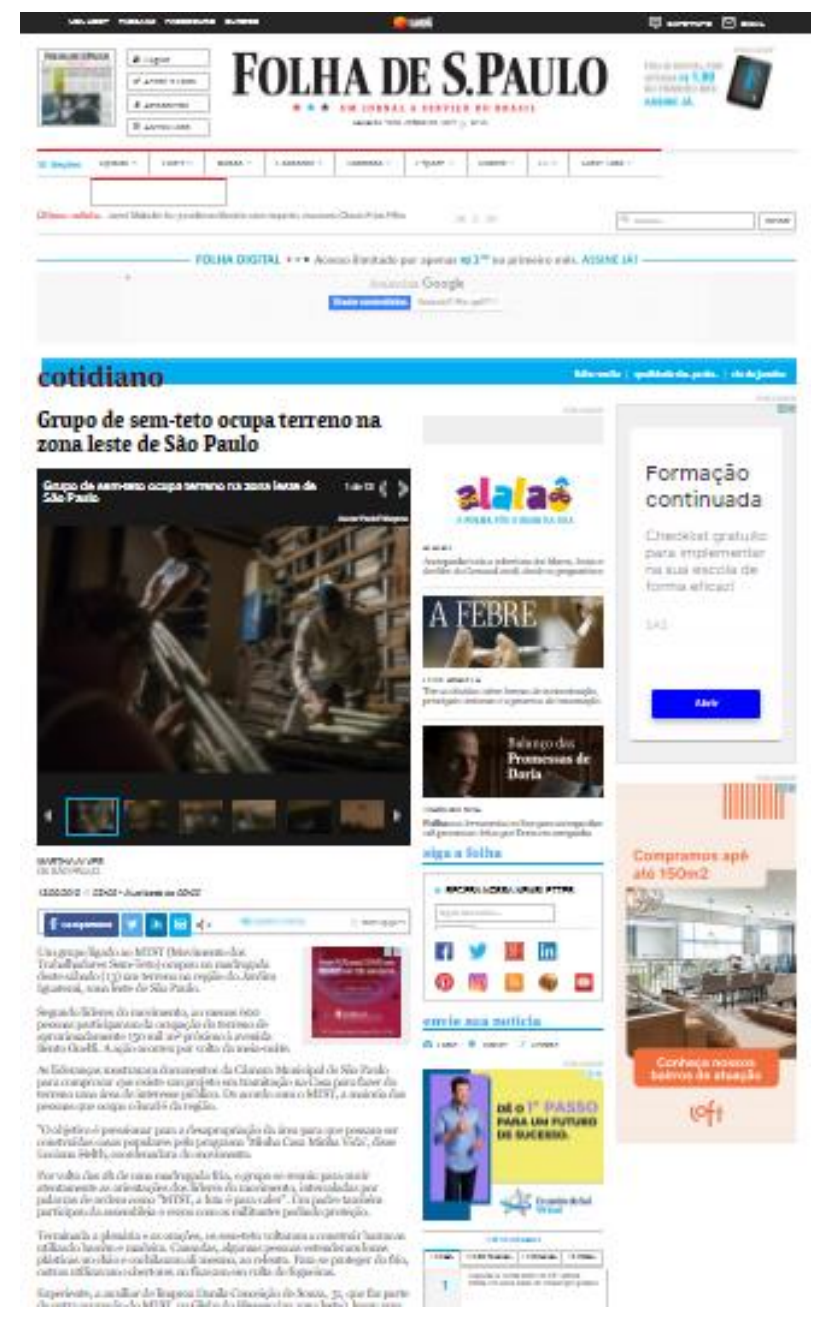

Imagem 1 - Reportagem 5

Fonte: Folha de S. Paulo, 2014.

As demais reportagens utilizaram o termo invasão, com eventual emprego do vocábulo ocupação e variantes, neste caso, com o provável intuito de evitar a repetição das mesmas expressões no texto ou então sempre entre aspas, como no texto da reportagem 2 (Imagem 2). 


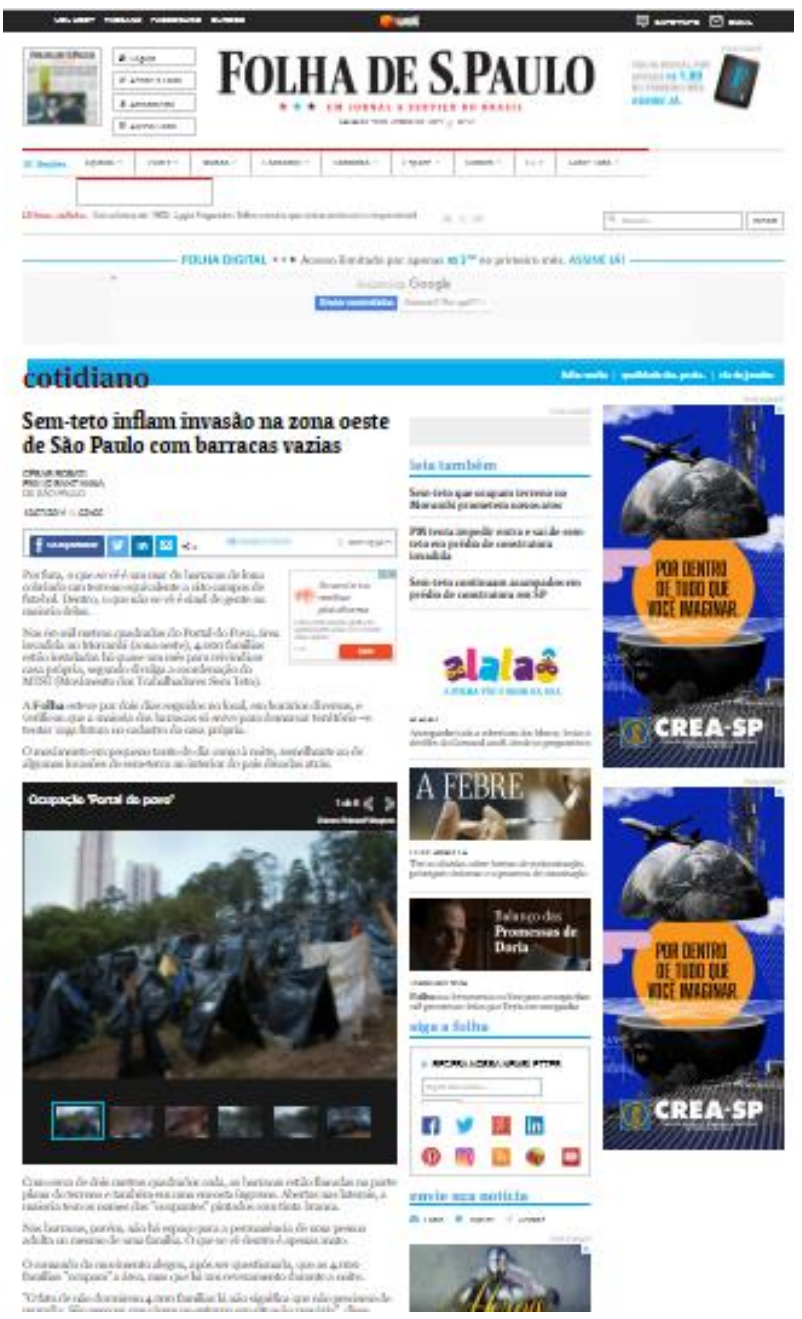

Imagem 2 - Reportagem 2

Fonte: Folha de S. Paulo, 2015.

A observação permitiu constatar que houve um progressivo aumento do número de fontes entrevistadas nas reportagens, tanto no que tange aos integrantes ou apoiadores do MTST (totalizando 28 na amostra) quanto de outros tipos de fontes (total de 15). A diversificação das fontes é um procedimento que permite trazer para o texto diferentes pontos de vista,_embora a seleção não equivalha necessariamente a uma representação qualitativa, a depender do que é reproduzido na matéria.

Na tipologia apresentada por Lage (2001), as fontes oficiais são os porta-vozes das instituições, sejam elas públicas ou privadas, e de organizações, associações ou movimentos sociais. Essas trazem, como a própria expressão indica, as vozes oficiais dessas entidades - em regra, as versões mais adequadas a seus propósitos -, ao passo que as fontes 
oficiosas muitas vezes falam por instituições e entidades sem serem credenciadas para isso, embora as informações trazidas possam ser tão ou até mais relevantes do ponto de vista da diversificação de pontos de vista e do fornecimento de informações exclusivas.

$\mathrm{Na}$ amostra selecionada, temos como fontes oficiais o MTST (por comunicados), Guilherme Boulos e outros líderes do movimento (totalizando 10) e representantes de órgãos públicos ou privados (6 ao todo). No caso das fontes oficiosas, há uma ocorrência na reportagem de número 3 (Imagem 3): um policial atuando como segurança privado, que acaba por prestar informações relevantes para a interpretação dos fatos narrados, uma vez que suas declarações davam indícios de como os policiais viam o movimento e atuavam em relação a ele. Em sua fala, o segurança relaciona a ocorrência de roubos de veículos à presença dos sem-teto em área vizinha a um condomínio. 


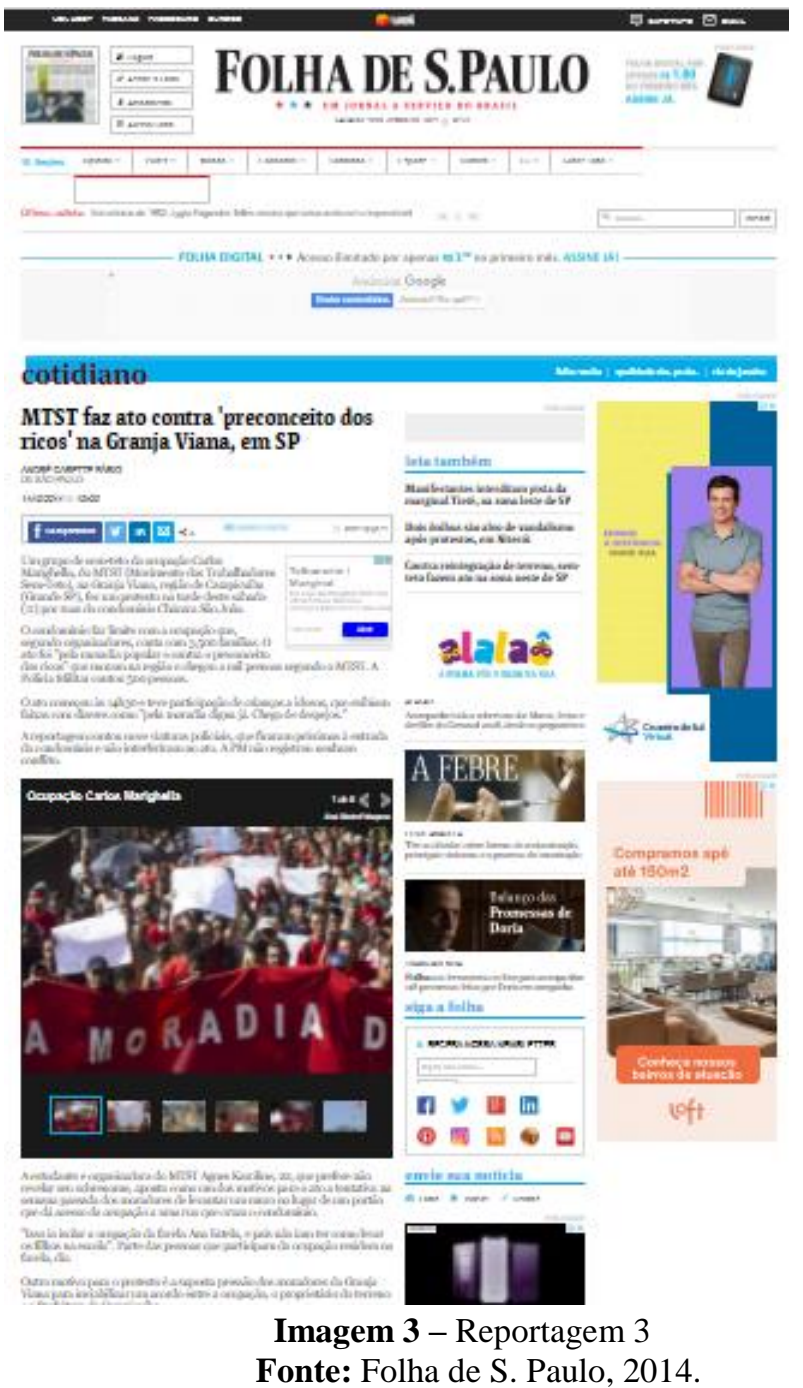

Já as fontes classificadas por Lage (2001) como testemunhas são as verdadeiras protagonistas das histórias relatadas, sejam aquelas que realizam ações de ocupação ou de resistência à ocupação, como no caso de vizinhos. Essas fontes podem oferecer um relato mais autêntico das experiências vividas e de suas motivações, neste caso, das razões para ocupar e realizar protestos ou, de outro lado, de reação a essas ações e sobre os impactos causados por elas. A observação da amostra identificou 16 testemunhas do MTST (10 ocupantes e 6 apoiadores) e de outro lado, 8 testemunhas (moradores).

Especificamente uma das reportagens, a de número 5, demonstra maior preocupação em entrevistar o movimento: 6 ocupantes (testemunhas) e mais uma fonte oficial do MTST. No mesmo texto, é ouvido um representante da Polícia Militar (oficial). Essa reportagem também utiliza a expressão "ocupar" tanto no título como no corpo da matéria, 
provavelmente por uma opção da repórter, uma vez que não coincidia com o padrão adotado pelo jornal.

Uma das reportagens (número 6 - Imagem 4) não entrevista nenhum ocupante (testemunha), citando o MTST em comunicado e reproduzindo uma declaração de Guilherme Boulos (fontes oficiais).

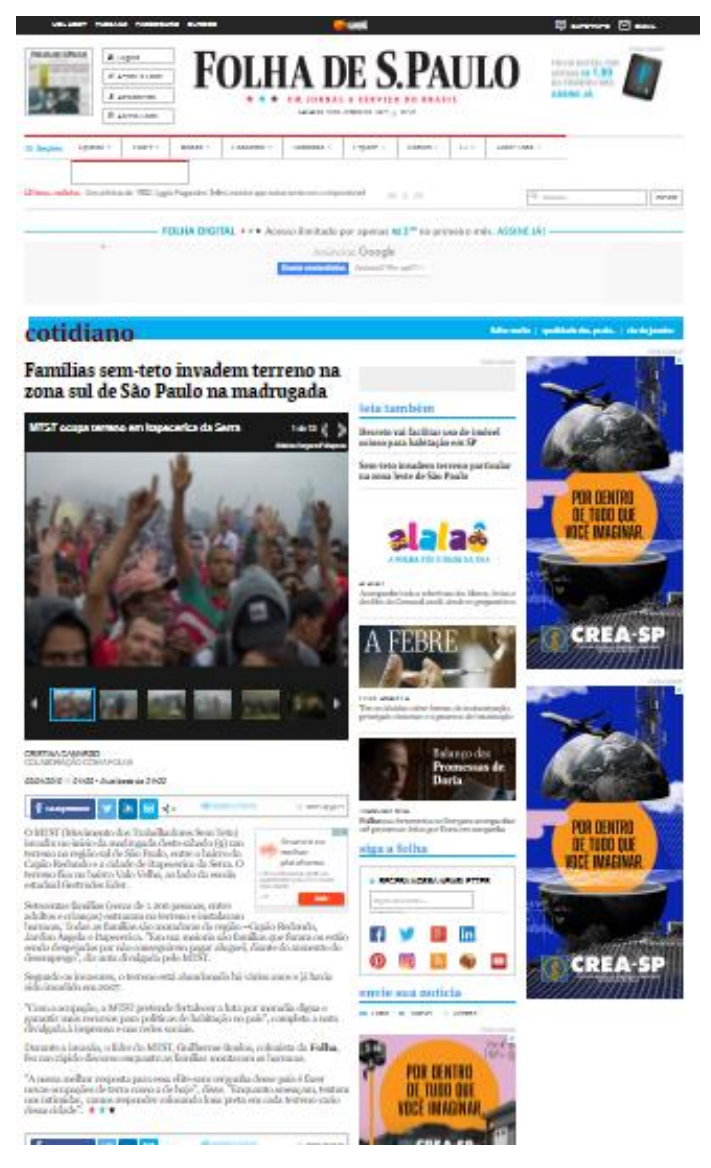

Imagem 4 - Reportagem 6

Fonte: Folha de S. Paulo, 2016.

Na reportagem de número 8 (Imagem 5), é dado destaque aos depoimentos de moradores do entorno de uma ocupação (6 fontes ouvidas - testemunhas), alguns aparecendo por mais de uma vez no texto e relatando sentirem-se prejudicados, seja por verem restringido seu espaço de circulação, seja por uma possível desvalorização de seus imóveis caso a ocupação ao lado do condomínio persistisse. Da parte dos sem-teto, Guilherme Boulos (fonte oficial) tem reproduzida uma declaração e são ouvidas 3 testemunhas: uma ocupante e duas vendedoras de lanches, bebidas e café aos acampados. O jornal refere-se ao acampamento dos sem-teto, tanto no título como no corpo do texto, como "megainvasão". 


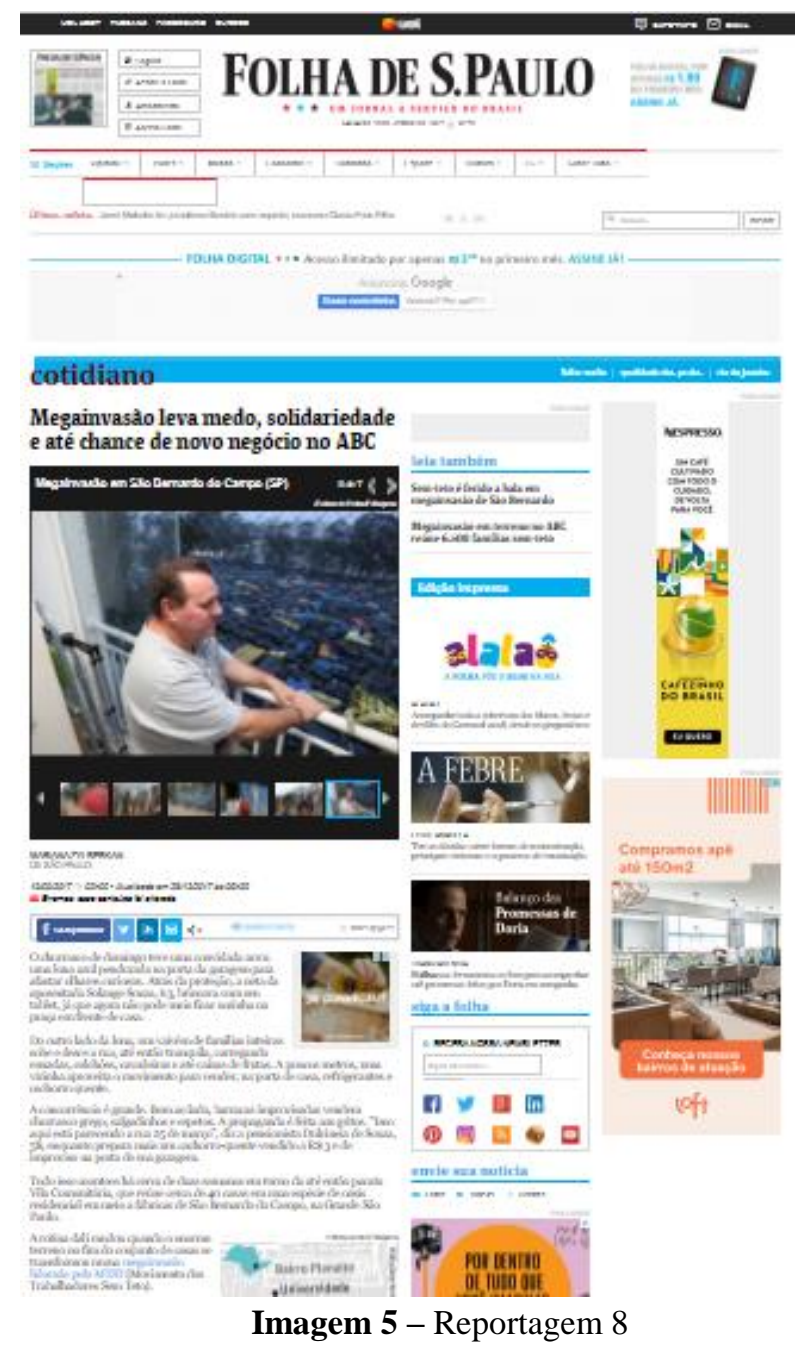

Fonte: Folha de S. Paulo, 2017.

Por sua vez, os experts, de acordo com Lage, são especialistas em determinados temas, aptos a interpretar os eventos relatados a partir de sua área de conhecimento. Em relação a essa categoria, na amostra analisada não foram entrevistados especialistas, o que evidencia a ausência de um esforço de interpretação e análise dos fatos noticiados. Tampouco foram ouvidos analistas credenciados, a fim de "repercutir" as informações veiculadas pelas reportagens.

Quanto à contextualização dos fatos narrados nas reportagens, observa-se que em nenhuma delas o jornal busca aprofundar as causas que levaram às situações abordadas, seja de ocupações ou manifestações, o que poderia contribuir para uma compreensão mais ampla 
do que é relatado. Tal lacuna acaba por conferir a esses fatos um caráter episódico, apartado de uma realidade mais abrangente. Dessa forma, as reportagens deixam de estabelecer um nexo entre as ações dos sem-teto e a real dimensão do problema da habitação no Brasil. Ressalta-se, ainda, que em nenhum texto analisado faz-se qualquer menção ao direito à moradia.

Em termos de angulação ou enfoque dos textos, verifica-se que três reportagens as de números 2, 3 e 8 - são claramente parciais: respectivamente, devido ao tom de desconfiança e descrédito adotados, ao sugerir que o MTST "infla” o número de ocupantes de um acampamento sem, entretanto, procurar entrevistar os sem-teto ou tomar conhecimento da dinâmica da ocupação; ao levantar dúvidas sobre a legitimidade do protesto realizado pelos sem-teto contra o preconceito demonstrado pela vizinhança de uma ocupação; e ao enfatizar os transtornos causados aos vizinhos de uma outra.

São reproduzidos, nos dois últimos textos, depoimentos relacionando a presença do movimento a episódios de roubo e tráfico de drogas, além de variadas queixas de vizinhos às ocupações sem a devida apresentação do contraditório - este, um cânone jornalístico. Ao colocar em destaque tais declarações sem ouvir o outro lado e sem a preocupação de mostrar aquilo que é verdadeiramente relevante para a compreensão do problema da moradia, a Folha deixa de contribuir para o aprofundamento da questão.

Tais constatações, especificamente, colocam a Folha em desacordo com seu próprio Manual de Redação, em que estão explicitados seus princípios e procedimentos editoriais. Em particular, a busca pelo pluralismo (FOLHA DE S. PAULO, 2011, p. 48) e pela contextualização (FOLHA DE S. PAULO, 2011, p. 23) exigiriam uma cobertura que desse conta da complexidade do problema da moradia no Brasil, o que seria determinante para o entendimento de um dos maiores dramas sociais do país e o reconhecimento da necessidade de concretização desse direito fundamental.

Realizou-se, ainda, a análise das imagens mostradas nas reportagens, por meio de fotografias individuais ou dispostas em galerias, observando-se os planos fotográficos, que representam a organização dos elementos no enquadramento feito pelo fotógrafo. ${ }^{14}$ Em uma

\footnotetext{
14 Os planos variam de acordo com o que se escolhe mostrar em cada fotografia e o distanciamento entre a câmera e o objeto em destaque. A tipologia utilizada baseou-se em PALACIN, 2012 e PRÄKEL, 2010, estando dividida em:
}

Grande plano geral - Utilizado para evidenciar o ambiente como elemento principal. Nele, a área enquadrada é preenchida em sua maior parte pelo ambiente e o sujeito/objeto ocupa um pequeno espaço na foto. 
das reportagens da amostra, a de número 7 (Imagem 6) é utilizado também um vídeo da TV Folha.

De forma geral, nota-se nas galerias de fotos ou fotografias apresentadas no corpo das reportagens uma maior utilização de planos gerais (25 ao todo) e uma progressiva utilização de planos médios (22 ocorrências), conforme se avança no tempo, para mostrar as ocupações e seus protagonistas. Quando comparados aos planos gerais, os planos médios “aproximam" os objetos fotografados do leitor/internauta, embora não necessariamente os individualizem. De forma geral, os ocupantes são mostrados em conjunto, reunidos em alguma atividade, mas não identificados individualmente por legendas. Nas galerias, uma só legenda, de cunho genérico, é utilizada para todas as fotografias. Fotos em grande plano geral totalizaram 6 e, em primeiro plano, 2.

Na reportagem de número 7 , que trata da prisão de Guilherme Boulos sob acusação de incitação à violência em episódio de desocupação em São Mateus, Zona Leste de São Paulo, o jornal incluiu um vídeo da TV Folha (1’06) com entrevista a Boulos (enquadrado em primeiro plano), em que o coordenador do MTST afirma ter havido violência por parte da polícia contra as famílias e explica por que, em sua opinião, a prisão foi política.

Plano geral - Há uma interação entre o sujeito/objeto e o ambiente, formando ambos um conjunto que se completa. Na imagem, é possível destacar-se o sujeito/objeto em relação ao espaço.

Plano médio - Plano mais utilizado para fotografar pessoas, engloba desde os pés até a cabeça, podendo variar com o enquadramento cuja linha inferior da fotografia faz um corte na cintura ou no joelho. Neste caso, o sujeito ou objeto ocupa a maior parte da área enquadrada.

Primeiro plano - O destaque é o sujeito/objeto enquadrado. Este plano "isola" o sujeito, dando menor destaque ao ambiente em que se encontra e evidencia expressões e gestos. 


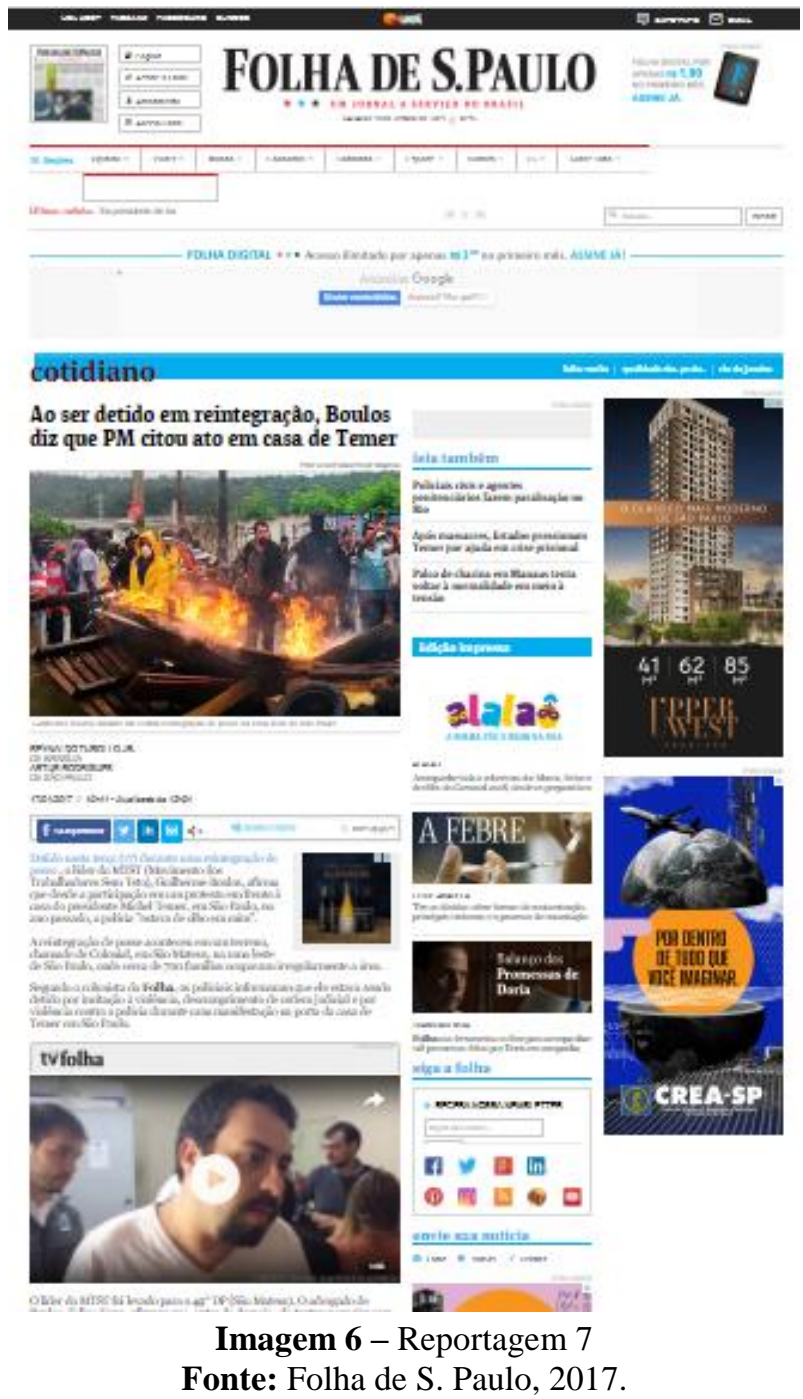

\section{CONSIDERAÇÕES}

A voz e o projeto político do MTST ganharam espaço na Folha de S. Paulo, por meio da coluna de seu líder, Guilherme Boulos, no site do jornal. Abria-se, dessa forma, uma possibilidade de apresentar ao público a visão de mundo, as reivindicações e bandeiras do movimento, a principal delas o reconhecimento do direito à moradia.

Habitualmente criminalizados por atentarem contra o direto à propriedade, os sem-teto conquistaram, então, um canal de diálogo com o leitorado do jornal de maior circulação nacional, o que, a princípio, permitiria expor uma outra realidade, desconhecida ou ignorada por grande parte desses leitores.

Ao que tudo indica, o fato de as ações do movimento à época terem ganhado notoriedade e visibilidade despertou a atenção e motivou o convite por parte do jornal ante a 
possibilidade de elevar sua reputação como veículo que busca a pluralidade, o que, por sua vez, poderia ampliar a conquista de novos leitores. Nesse sentido, a análise quantitativa mostra que o espaço de cobertura concentrou-se no período próximo à estreia de Guilherme Boulos como colunista, reduzindo-se de forma acentuada ao longo do período posterior.

A análise qualitativa de reportagens do jornal demonstra que os sem-teto foram representados de forma prevalente como "invasores" e não como "ocupantes", conforme a terminologia do MTST, a despeito de o movimento e seus integrantes terem aparecido de maneira progressiva como entrevistados e por um número maior de vezes que outras fontes envolvidas nos fatos descritos. Verifica-se que suas fontes oficiais ou testemunhais foram contempladas nas reportagens, com destaque para uma entrevista em vídeo de mais de um minuto com Guilherme Boulos em uma delas.

Entretanto, em três das reportagens, os sem-teto são mostrados com estranhamento, desconfiança ou como alvo de repúdio por parte de moradores vizinhos às ocupações sem o devido contraditório, nesse caso indicando um não-reconhecimento desse grupo como interlocutor qualificado no espaço da cobertura jornalística.

A não-contextualização dos fatos cobertos - sejam ocupações, manifestações ou ações de resistência a reintegrações de posse - dificulta, ainda, o pleno entendimento das condições que os originaram. Essa lacuna contribui para a naturalização da condição dos semteto, uma vez que tal realidade aparece como algo dado, dificultando a compreensão da legitimidade da luta pela efetivação do direito à moradia no país. Esse direito constitucional, por sua vez, não é citado em nenhuma das reportagens.

A análise da representação imagética dos sem-teto na amostra demonstra, de forma geral, distanciamento em relação aos integrantes do grupo, que aparecem nas fotografias ou galerias de fotos em conjunto, sem individualização ou identificação em legendas, embora tenha sido, por uma vez, veiculada entrevista em vídeo com seu líder.

Dessa forma, é possível concluir que, em que pese a cobertura jornalística em questão ter concedido espaço ao movimento, de forma geral, o veículo deixou de contribuir de forma plena para a compreensão da importância da efetividade do direito à moradia no país. 


\section{REFERÊNCIAS}

ALVES, M.. Grupo de sem-teto ocupa terreno na zona leste de São Paulo. Folha de S. Paulo, 13 jun. 2015. Cotidiano. Disponível em: https://www1.folha.uol.com.br/cotidiano/2015/06/1641743-grupode-sem-teto-ocupa-terreno-na-zona-leste-de-sao-paulo.shtml. Acesso em 20 jun. 2021.

BOULOS, G. Por que ocupamos? Uma introdução à luta dos sem-teto. São Paulo: Autonomia Literária, 2014.

. Última coluna. Folha de S. Paulo, São Paulo, 9 mar. 2017. Disponível em: https://www1.folha.uol.com.br/colunas/guilhermeboulos/2017/03/1864959-ultima-coluna.shtml. Acesso em 20 jun. 2021.

BRASIL. Constituição da República Federativa do Brasil: promulgada em 5 de outubro de 1988. Disponível em: http://www.planalto.gov.br/ccivil_03/constituicao/constituicao.htm. Acesso em 10 jun. 2021.

CAMARGO, C. MTST invade mais um terreno particular na Grande São Paulo. Folha de S. Paulo, 23 mai. 2015. Cotidiano. Disponível em: https://www1.folha.uol.com.br/cotidiano/2015/05/1632852mtst-invade-mais-um-terreno-particular-na-grande-sao-paulo.shtml. Acesso em 20 jun. 2021.

Famílias sem-teto invadem terreno na zona sul de São Paulo na madrugada. Folha de S. Paulo, 9 abr. 2016. Cotidiano. Disponível em: https://www1.folha.uol.com.br/cotidiano/2016/04/1759230familias-sem-teto-invadem-terreno-de-mil-metros-quadrados-em-itapecerica.shtml. Acesso em 20 jun. 2021.

FÁBIO, A. C. MTST faz ato contra 'preconceito dos ricos' na Granja Viana, em SP. Folha de S. Paulo, 11 out. 2014. Cotidiano. Disponível em: https://www1.folha.uol.com.br/cotidiano/2014/10/1531173-mtst-faz-ato-contra-preconceito-dos-ricosna-granja-viana-em-sp.shtml. Acesso em 20 jun. 2021.

FAIRCLOUGH, N. Discurso e Mudança Social. Trad. Izabel Magalhães. Brasília: UNB, 2001.

FOLHA DE S. PAULO. Manual da Redação. São Paulo: Publifolha, 2011.

Manual da Redação. São Paulo: Publifolha, 2018.

FOLHA DE S. PAULO. Perfil do leitor. Folha de S. Paulo. Disponível em:

http://www.publicidade.folha.com.br/folha/perfil_do_leitor.shtml. Acesso em 25 nov. 2017.

FUNDAÇÃO JOÃO PINHEIRO. Estatística e Informações: demografia e indicadores sociais: Déficit habitacional no Brasil, 2015. Diretoria de Estatística e Informações (DIREI). Coordenação das Estatísticas Urbano Ambientais. Belo Horizonte, Minas Gerais, 2018. Disponível em: http://www.bibliotecadigital.mg.gov.br/consulta/consultaDetalheDocumento.php?iCodDocumento=76 871. Acesso em 15 jun. 2021.

GOULART, D.C. O anticapitalismo do Movimento dos Trabalhadores Sem-Teto - MTST. 2011. Tese (Doutorado em Ciências Sociais) - Faculdade de Filosofia e Ciências, Universidade Estadual Paulista, Marília, 2011.

IBGE. Pesquisa Nacional por Amostragem de Domicílios - Pnad, 2015. Disponível em: https://biblioteca.ibge.gov.br/visualizacao/livros/liv98887.pdf. Acesso em 15 jun. 2021. 
LAGE, N. A reportagem: teoria e técnica da entrevista e pesquisa jornalística. Rio de Janeiro: Record, 2001.

MARQUES DE MELO, J.; ASSIS, F. Gêneros Jornalísticos no Brasil. São Paulo: Metodista, 2010.

MARTINS, V. G. Questão de Filosofia. Folha de S. Paulo, 29 de junho de 2014. Disponível em: https://m.folha.uol.com.br/colunas/veraguimaraesmartins/2014/06/1478111-questao-de-

filosofia.shtml?mobile. Acesso em 20 jun. 2021.

MEDINA, C. Notícia, um produto à venda: Jornalismo na sociedade urbana e industrial. São Paulo: Summus Editorial, 1978.

PALACIN, V. Fotografia - Teoria e Prática. São Paulo: Saraiva, 2012.

PANSIERI, F. Eficácia e vinculação dos direitos sociais: reflexões a partir do direito à moradia. São Paulo: Saraiva, 2012.

PRÄKEL, D. Composição. Porto Alegre: Bookman, 2010.

RESENDE, V. M.; RAMALHO, V. Análise de Discurso Crítica. São Paulo: Contexto, 2006.

. Análise de discurso (para a) crítica. O texto como material de pesquisa. São Paulo:

Contexto, 2011.

ROLNIK, R. Guerra dos Lugares: a colonização da terra e da moradia na era das finanças. São Paulo: Boitempo, 2015.

ROSATI, C.; SANT'ANNA, E. Sem-teto inflam invasão na zona oeste de São Paulo com barracas vazias. Folha de S. Paulo, 19 jul. 2014, Cotidiano. Disponível em:

https://www1.folha.uol.com.br/cotidiano/2014/07/1488391-sem-teto-inflam-invasao-na-zona-oestede-sao-paulo-com-barracas-vazias.shtml?mobile. Acesso em 20 jun. 2021.

SIMÕES, G; CAMPOS, M.; RAFAEL, R. MTST: 20 anos de história. Luta, organização e esperança nas periferias do Brasil. São Paulo: Autonomia Literária, 2017.

TUROLlO JR, R. Em 1 mês, SP ganha acampamento com 8.000 famílias de sem-teto. Folha de $\mathbf{S}$. Paulo, 8 jan. 2014. Cotidiano, Disponível em: https://www1.folha.uol.com.br/cotidiano/2014/01/1394702-em-1-mes-sp-ganha-acampamento-com8000-familias-de-sem-teto.shtml. Acesso em 20 jun. 2021.

.; RODRIGUES, A. Ao ser detido em reintegração, Boulos diz que PM citou ato em casa de Temer. Folha de S. Paulo, 17 jan. 2017. Cotidiano. Disponível em:

https://www1.folha.uol.com.br/cotidiano/2017/01/1850504-ao-ser-detido-em-reintegracao-boulos-dizque-pm-citou-ato-em-casa-de-temer.shtml. Acesso em 20 jun. 2021.

ZYLBERKAN, M. Megainvasão leva medo, solidariedade e até chance de novo negócio no ABC.

Folha de S. Paulo, 19 set. 2017. Cotidiano. Disponível em:

https://www1.folha.uol.com.br/cotidiano/2017/09/1919711-megainvasao-leva-medo-solidariedade-eate-chance-de-novo-negocio-no-abc.shtml. Acesso em 20 jun. 2021. 
Doutora em Direitos Humanos pela Faculdade de Direito da Universidade de São Paulo. Mestre em Ciências da Comunicação pela Escola de Comunicações e Artes da Universidade de São Paulo (ECA-USP). Jornalista graduada pela Faculdade Cásper Líbero. Especialização em Gestão Estratégica em Comunicação Organizacional e Relações Públicas (Gestcorp) pela ECA-USP. Experiência profissional em jornalismo impresso, jornalismo digital, comunicação organizacional e docência em cursos de Comunicação.

\section{@ $\odot \Theta 0$}

Esta obra está licenciada com uma Licença

Creative Commons Atribuição-NãoComercial-CompartilhaIgual 4.0 Internacional 